\title{
EDUCAÇÃO, DIVERSIDADE E RACISMO: Repensando a Formação do/a Professor/a
}

\author{
EDUCATION, DIVERSITY AND RACISM: \\ Rethink the Formation of a Professor
}

Elenice Silva Ferreira1

\begin{abstract}
RESUMO
O presente trabalho é o resultado da experiência como docente no curso de extensão: "Educação e culturas afrobrasileiras", promovido pelo ODEERE/UESB2 ${ }^{2}$ c cujo objetivo é a promoção de discussões acerca da ancestralidade do povo negro e a sua trajetória histórica no Brasil, com vistas à formação continuada do educador. 0 texto vem propor uma reflexão acerca da necessidade urgente de se repensar a prática educativa hoje, no que diz respeito ao ensino da história da África e da cultura afro-brasileira na educação básica, vindo à tona a partir da promulgação da lei $10.639 / 2003^{3}$. Iniciamos pela reflexão sobre novo papel do professor face aos desafios apresentados pela sociedade que se redesenha neste início de século, marcada pela globalização da cultura, favorecida pela velocidade da informação e, paradoxalmente, pela negação à diversidade. Nessa perspectiva, buscamos discutir como na história da educação brasileira, a ausência de uma reflexão sobre as relações raciais no planejamento escolar tem impedido a promoção de relações interpessoais respeitáveis e igualitárias entre os agentes sociais que integram o cotidiano da escola. Fundamentado nos estudos de NÓVOA (1992), MUNANGA (2005), FERNANDES (1965), CANDAU (1999), o texto traz reflexões referentes à formação continuada do educador como sendo uma prioridade em qualquer proposta de reforma educativa. 0 mesmo se encerra mostrando, de forma resumida, as propostas construídas pelo ODEERE junto à comunidade da região sudoeste da Bahia. Tais propostas vêm ressaltar, assim, o relevante papel da Universidade como instituição de formação política, de promoção e disseminação do conhecimento.
\end{abstract}

Palavras-chave: Diversidade. Escola. Prática educativa.

\section{ABSTRACT:}

This work is the result of experience as a teacher in extension: "Education and cultures Afro-Brazilian", promoted by ODEERE/UESB, whose goal is the promotion of discussions about pure black people and their historical trajectory in Brazil, training continued educator. The text proposes a reflection about the urgent need to rethink the educational practice today, for the teaching of history of African and Afro-Brazilian culture in basic education, come to light from the promulgation of law 10.639/2003. We start by thinking about the new role of the teacher in the face of the challenges presented by the society which redraws itself at the beginning of the century, marked by the globalization of culture, favored by the speed of information and, paradoxically, by denial to diversity. From this perspective, we discuss how Brazilian in the history of education, the absence of a reflection on racial relations in school planning has prevented the promotion of interpersonal respectable relationship and equal decision-making among the social actors that integrate the daily life of the school. Based on studies of NÓVOA (1992), MUNANGA (2005), FERNANDES (1965), CANDAU (1999), the text brings thoughts regarding continuing educator training as a priority in any educational proposal reformulation. The same ends up showing concisely, the proposals built at ODEERE together with the community of the region South-West of Bahia. These proposals come out, so the relevant role of the University as an institution of political formation, promotion and dissemination of knowledge.

Keywords: Diversity. School. Educational Practice.

1 Professora do Departamento de Ciências Humanas e Letras da Universidade Estadual do Sudoeste da Bahia-UESB. Mestranda em Educação-PUC/MG. Membro do grupo de pesquisa "Educação e Relações Étnicas com Ênfase em Culturas Afro-brasileiras", CNPq e docente no programa de extensão universitária do Órgão de Educação e Relações Étnico-raciais com Ênfase em Culturas Afro-Brasileiras, ODEERE/UESB. E-mails: elenicesf@hotmail.com; elenicesf@hotmail.com.

2 Órgão de Educação e Relações Étnico-raciais com Ênfase em Culturas Afro-Brasileiras, da Universidade Estadual do Sudoeste da Bahia.

3 Atualmente 11.645/2008, que estabelece as diretrizes e bases da educação nacional, para incluir no currículo oficial da rede de ensino, a obrigatoriedade da temática "História e Cultura Afro-Brasileira e Indígena. Uma conquista justa pelos indígenas brasileiros. 


\section{REFLEXÕES PRELIMINARES...}

\section{Caminhante, o caminho se faz no caminhar (Edgar Morin, 1996) ${ }^{4}$}

De acordo com o historiador inglês Peter Burke (1992), a História Nacional dominante no século XIX teve o seu campo de estudos restrito ao âmbito do sócio-político, atribuindo, portanto, pouca importância ao estudo local e regional. As conseqüências dessa postura acarretaram muitos prejuízos para o saber e, principalmente, para a construção de identidades de grupos excluídos socialmente, a exemplo, a população negra. Nessa perspectiva, a história do povo negro no Brasil, fora do período colonial-escravocrata, é marcada, demasiadamente, pela invisibilidade de sua presença na chamada "história oficial". Nesse sentido, o intelectual Milton Santos (1992) costumava afirmar que a discussão sobre a história do negro no Brasil é prisioneira de uma ética enviesada, quando não, é jogada para um amanhã que nunca chega. De fato, o renomado intelectual tinha razão. Hoje, após anos de luta por visibilidade e reconhecimento cultural e histórico de seu grupo étnico, ainda presenciamos um falso discurso em torno das questões do negro na sociedade brasileira permeado pela idéia de uma democracia racial ${ }^{5}$.

De acordo com Rios e Matos (2005), em seu trabalho "Memórias do cativeiro"6, mesmo redefinindo os significados emprestados à memória do passado escravo, o povo negro substitui hoje a antiga invisibilidade por uma incisiva afirmação de sua identidade negra, não obstante, convive ainda com a herança racista que permanece nas atitudes de pessoas que insistem em sustentar a crença de uma pretensa superioridade branca.

No que se refere ao conhecimento escolar, percebe-se ainda um caráter de "branqueamento" em nosso currículo, programas escolares e materiais pedagógicos. De acordo com Cavalleiro (2000), quase sem exceção os negros aparecem nesses materiais apenas para ilustrar o período escravista do Brasil-Colônia ou, então, para ilustrar situações de subserviência ou de desprestígio social.

Conferência proferida na PUC/SP, em outubro de 1996. 5 Expressão criada na primeira metade do século XX para difundir a crença de que, se os negros não
atingem os mesmos patamares que os não-negros, é por falta de competência ou interesse, desconsiderando as desigualdades históricas que a estrutura social expôs aos negros. Durante o Regime Militar no Brasil, o governo centralizador, através do "Mito" da democracia racial, se encarregou de disseminar a ideologia de uma sociedade igualitária em que as raças se irmanam. 0 mito da democracia racial teve em Florestan Fernandes o seu mais severo crítico. (Cf. Fernandes, A integração do negro na sociedade de classes. Vol. 1. São Paulo: Ática, 1978, p.43-270)

6 Memórias do cativeiro. Rio de Janeiro: Civilização Brasileira, 2005. 
Nesse sentido, é possível afirmar que a história e a cultura do negro estão na escola pela presença dos negros que lá se encontram, mas não devidamente valorizados dentro dos projetos pedagógicos, currículos ou materiais didáticos. Nessa perspectiva, a escola ignora a diversidade de sujeitos que se encontra presente em seu cotidiano. Uma diversidade de sujeitos com diferentes crenças, modos de vida e visões de mundo, entretanto, tratados de modo "igual". Aliás, sobre essa questão, o intelectual português Boaventura de Sousa Santos (2003) já nos chamava a atenção quando afirmava que: "devemos lutar pela igualdade toda vez que a diferença nos inferioriza, mas também devemos lutar pela diferença toda vez que a igualdade nos descaracteriza" (SANTOS, 2003, p.462). Enfim, a educação que deveria ser compreendida como um direito universal, dentro dessa proposição apontada, acaba por converter-se em algo competitivo, dualizado e seletivo social e culturalmente.

Com a emergência dos dispositivos legais voltados para a promoção da educação para as relações étnico-raciais na escola, o debate acerca da educação e diversidade passa a adotar novas nuances. Nesse sentido, a legislação que põe em evidência a necessidade de se repensar a presença das discussões sobre a história e a cultura do povo negro na educação básica se insere no que ficou conhecido como "Ações Afirmativas"7, e, por conseguinte, a questão da formação do/a professor/a passa a agregar novos elementos. Neste caso, é pertinente afirmar que não apenas o currículo ressignificado e as condições materiais da escola constituem elementos indispensáveis para a construção de uma educação de qualidade para todos (qualidade aqui não no sentido mercadológico), mas a formação do/a educador/a se apresenta como fator determinante na construção de uma nova mentalidade no processo educativo que leve em consideração o reconhecimento e a valorização do legado cultural dos povos africanos e seus descendentes.

É nessa direção que buscam caminhar as propostas de pós-graduação latu sensu, através do curso de especialização em Antropologia com Ênfase em Culturas Afro-brasileiras e dos cursos de extensão Educação e Culturas Afro-brasileiras e Didática para o ensino de Culturas Afro-brasileiras promovidos pelo ODEERE/UESB ${ }^{8}$ que serão discutidos no presente trabalho.

\footnotetext{
7 De acordo com GONÇALVES e SILVA (2004), ações afirmativas podem ser definidas como "[...] um conjunto de ações políticas dirigidas à correção de desigualdades raciais e sociais, orientadas para oferta de tratamento diferenciado com vistas a corrigir desvantagens e marginalização criadas e mantidas por estrutura social excludente e discriminatória." (GONÇALVES \& SILVA, 2004, p. 12).

8 É válido ressaltar que fazem parte do conjunto de atividades do ODEREE/UESB o Projeto ODEEREZINHO-Educação e Culturas Afro-brasileiras para crianças e adolescentes e os eventos: Semana de Educação da Pertença Afro-brasileira, Encontro de Combate a Discriminação Étnica e a tradição do Caruru de Cosme Damião Erês, Ibejis e Wunje que não serão objeto de discussão no presente trabalho.
} 


\section{AS LEIS E A EDUCAÇÃO PARA AS RELAÇÕES ÉTNICO-RACIAIS NA EDUCAÇÃO BÁSICA, UMA CONQUISTA DA LUTA ANTI-RACISTA}

Sabe-se que a formação cultural do Brasil se caracteriza pela fusão de diferentes etnias, pela contínua ocupação de diferentes regiões geográficas, pela diversidade de fisionomias e paisagens, e também pela multiplicação de visão de miscigenação em sentido amplo, algumas ainda presas à desinformação e ao preconceito. Nesse sentido, quando se discute as relações étnico-raciais no Brasil, percebemos que chegamos ao século XXI com uma sociedade prenhe de contradições e paradoxos. Sobre essa questão, o intelectual Otávio lanni (2003) afirma categoricamente que

\footnotetext{
é assim que o mundo ingressa no século XXI, debatendo-se com a questão racial, tanto quanto com a intolerância religiosa, a contradição natureza e sociedade, as hierarquias masculino-feminino, as tensões e lutas de classes. São dilemas que se desenvolvem com a modernidade, demonstrando que o "desencantamento com 0 mundo", enquanto metáfora do esclarecimento e da emancipação continua a ser desafiada por preconceitos e superstições, intolerâncias e racismos, irracionalismos e idiossincrasias, interesses e ideologias. (IANNI, Otávio, 2003, p. 2)
}

A história evidencia várias iniciativas tomadas a fim de que a relação de preconceito no que se refere às populações negras fosse superada. Os estudos de Santos (2005) vêm apontar como exemplo disso a mobilização do Movimento Negro, desde a década de 40, em favor da aprovação de legislações que pudessem garantir ao povo negro o reconhecimento da presença de sua história e de seu legado cultural em espaços até então ocupados pela cultura de outros grupos étnicos, neste caso, o povo branco.

Dessa luta vieram várias conquistas, a exemplo a aprovação da Constituição do Estado da Bahia, promulgada em 05 de outubro de 1989 e de Leis Orgânicas em diversas capitais brasileiras como Porto Alegre, Lei $n^{0}$ 6.889, promulgada em 05 de setembro de 1991; Belém, Lei $n^{0}$ 7.685, de 17 de janeiro de 1994; São Paulo, Lei n 11.973, de 4 de janeiro de 1996; Recife, promulgada em 04 de abril de 1990; Belo Horizonte, promulgada em 1990; Rio de Janeiro, promulgada em 05 de janeiro de 1990 (SANTOS, 2005), que previam a inclusão, por meio de leis, de disciplinas sobre a História dos Negros no Brasil e a História do Continente Africano nos ensinos fundamental e médio das redes estadual e municipal de ensino.

Como se pode ver, a luta pelo reconhecimento e pela incorporação do estudo da História da África e dos Africanos e a luta dos negros no Brasil no currículo escolar é uma luta antiga. 
Trata-se de uma luta histórica, sobretudo, do movimento social negro que remonta a década de 50. Já nessa época, foram feitas reivindicações para a inclusão do ensino da História da África e dos Africanos nos currículos das escolas de todo o país.

Com o fortalecimento das ações do Movimento Negro na década de 70 e de intelectuais envolvidos nessas lutas, várias conquistas foram alcançadas. Além da legislação mencionada acima, a Constituição de 1988 deu uma relevante contribuição ao reconhecer a Pluralidade Cultural Brasileira. Além deste reconhecimento, o novo texto constitucional ainda traz entre outros artigos, o artigo 242 alusivo à educação, ressaltando a necessidade de que "o ensino de História do Brasil levará em conta as contribuições das diferentes culturas e etnias para a formação do povo brasileiro". (BRASIL, 1988, art. 242).

Do mesmo modo, o texto da atual LDB aprovada em 1996 reservou espaço significativo à questão racial. Tais reconhecimentos oportunizados pela Constituição de 1988, pelas legislações estaduais e municipais supracitadas e pela LDB, redundaram na inclusão da temática da Pluralidade Cultural como um dos temas transversais a fazer parte dos Parâmetros Curriculares Nacionais ${ }^{9}$, os PCN, em 1997 (mesmo reconhecendo a contribuição dada por estes documentos no que se refere à discussão sobre a pluralidade cultural no Brasil, não podemos deixar passar desapercebidas as limitações com que a temática étnico-racial é tratada por tais "parâmetros", além do mais os mesmos, em muitas escolas por este Brasil afora, lamentavelmente, serviram apenas para decorar a estante do diretor).

É no bojo dessas conquistas que emerge a Lei 10.639/200310. Com a publicação da referida lei, o Conselho Nacional de Educação aprovou o Parecer CNE/ CP nº. 003/ 200411, que institui as Diretrizes Curriculares para a Educação das Relações Étnico-Raciais e o Ensino de História e Cultura Afro-Brasileiras e Africanas a serem trabalhadas pelos estabelecimentos de ensino de diferentes níveis e modalidades, cabendo aos sistemas de ensino, no âmbito de sua jurisdição, orientarem e promoverem a formação de professores/as e supervisionarem 0

9 De acordo com o MEC, os PCN possuem como intuito fornecer aos sistemas de ensino, subsídios à elaboração curricular. Dentre as diferentes áreas do conhecimento curricular convencional, buscou-se construir também como "parâmetro" o que ficou conhecido como Temas Transversais. Assim, algumas temáticas como Pluralidade Cultural, Ética, Meio Ambiente, dentre outras, deveriam transversalizar todo o currículo e todas as disciplinas. (BRASIL, 1997).

10 A Lei 10.639 foi sancionada pelo Presidente da República Luís Inácio Lula da Silva, em 9 de janeiro de 2003, e acrescenta dois artigos à LDB nº. 9.394, de 1996. A Lei determina que a História e a Cultura Afro-brasileira seja ensinada em todas as séries da educação básica. A lei determina também que esses conteúdos sejam ministrados no âmbito de todo o currículo escolar, especialmente nas áreas de Educação Artística, Literatura e História Brasileiras, e inclui o dia 20 de novembro como Dia Nacional da Consciência Negra no calendário escolar. 11 Aprovado em: 10 de março de 2004. Processo nº 23001.000215/2002-96. O referido documento regulamenta a alteração trazida à LDB nº. 9.394/96 pela Lei 10.639/03. 
cumprimento das diretrizes (SECAD, 2006). A partir da aprovação e da divulgação de tais documentos oficiais, o estudo da história e da cultura da África e Afro-brasileira passou a ser analisado sob outra perspectiva e, por conseguinte, a discussão sobre as relações étnico-raciais ocupou lugar de destaque.

Como se pode ver, o país tem uma vasta legislação no que se refere ao estudo da história do povo negro, sua raça ${ }^{12}$, seus descendentes e suas relações no meio social onde estão inseridos, entretanto ainda persiste em nossa sociedade um imaginário coletivo que privilegia os grupos e os valores oriundos do mundo ocidental, pouco valorizando os saberes ${ }^{13}$ dos povos com outras raízes culturais como a indígena e a africana.

Com o intuito de discutir a implementação da Lei 10.639/03, a SECAD ${ }^{14}$ realizou no ano de 2004 vários fóruns Estaduais de Educação e Diversidade Étnico-racial, em parcerias com 0 Movimento Negro Universidades Federais e Secretarias Estaduais de Educação. Percebe-se nessa iniciativa um modo de promover uma discussão que caminhe para a construção de projetos político-pedagógicos que subsidiem a ação de docentes, educadores/as em diferentes segmentos da sociedade para a construção de uma prática educativa anti-racista. Igualmente, algumas universidades brasileiras têm criado espaços de debates acerca das relações étnicoraciais na educação e, por conseguinte, criado programas de formação continuada dos/as educadores/as por meio de seus projetos de extensão ou, ainda, propondo a criação de cursos lato sensu na área.

\section{A EDUCAÇÃO PARA AS RELAÇÕES ÉTNICO-RACIAIS E A FORMAÇÃO CONTINUADA DE EDUCADORES/AS, ALGUNS PASSOS DADOS.}

Quando examinamos a história da educação, constatamos que nem sempre se cuidou adequadamente da importante questão da formação do/a professorla. Desde os tempos da colônia, quando os padres jesuítas eram os únicos educadores por aqui, a essa questão não foi dada prioridade. Com a expulsão dos religiosos, em 1759, a Coroa Portuguesa procurou

12 O conceito de Raça aqui está sendo discutido conforme aponta Stuart Hall (2006, p.63), como sendo uma categoria discursiva e não uma categoria biológica. Esse mesmo termo foi ressignificado pelo Movimento Negro, que atribuiu a ele uma conotação política.

13 Tomaz Tadeu da Silva (1995), ao discutir o currículo escolar, se refere a esses saberes como "territórios contestados". Ver: Cultura, Identidades sociais: territórios contestados. Petrópolis RJ: Vozes, 1995.

14 Secretaria de Educação Continuada, Alfabetização e Diversidade. Este órgão tem como objetivo planejar, orientar e acompanhar a formulação e a implementação de políticas educacionais, tendo em vista as diversidades de grupos étnico-raciais como as comunidades indígenas, a populações afro-descendentes dos meios urbano e rural e, neste caso, particularmente, as comunidades de áreas remanescentes de quilombos. (Cf.

Educação anti-racista : caminhos abertos pela Lei Federal no 10.639/03 / Secretaria de Educação Continuada, Alfabetização e Diversidade. - Brasília : Ministério da Educação, SECAD, 2005). 
substituí-los por professores leigos, desqualificados e mal pagos, piorando ainda mais o quadro educacional na colônia. (ROMANELLI, 2003).

Sacristán (1998) considera que a formação de educadores/as tem se constituído em uma das pedras angulares imprescindiveis a qualquer intento de renovação do sistema educativo. Essa contribuição do autor nos permite compreender a relevância que esta temática vem adquirindo nas últimas décadas, e que a sua necessidade se estende até a formação continuada do/a educador/a, sobretudo, após a promulgação da LDB n. 9.394/96. Esta em seu artigo 63, item III, rege que é função dos institutos superiores de educação manterem programas de educação continuada para os/as profissionais de educação dos diversos níveis. Nesta esteira, a universidade brasileira tem buscado ampliar o seu raio de ação e, através de seus programas de pós-graduação e extensão, tem favorecido uma maior abertura às discussões sobre as questões étnico-raciais com vistas a contribuir para a formação continuada15 dos/as educadores/as que atuam na educação básica.

Desse modo, a universidade vem atender, principalmente, as demandas dos sujeitos que buscam na academia instrumentos que venham subsidiar a sua prática docente, posto que a sua formação em magistério ou licenciaturas não prepara para trabalhar com os desafios colocados pela presença massiva de crianças e jovens negros em sala de aula.

E onde começa a ação da universidade no que se refere à formação continuada do/a educador/a para a educação das relações étnico-raciais? Para institucionalizar as ações previstas na legislação, o Ministério da Educação e Cultura, através do SEPPIR ${ }^{16}$ e do UNIAFRO17, se voltou para investir em projetos que concedem recursos financeiros para consolidar experiências de pesquisa e extensão, dotando de financiamento aquelas instituições de ensino de nível superior que tenham oficialmente Núcleos de Estudos de Culturas Afrobrasileiras - NEABs ou grupos correlatos. Nesse sentido, o trabalho desenvolvido pela UESB se insere nesta proposta.

Para atender a exigência do MEC, foi criado em 2006, na UESB, o Órgão de Educação e Relações Étnicas com Ênfase em Culturas Afro-brasileiras - ODEERE, em que discentes dos cursos de graduação, docentes, funcionários e pesquisadores passaram a desenvolver atividades de pesquisa, extensão e ensino em que se prevê agregar neste espaço

\footnotetext{
15 A opção pelo termo Formação Continuada utilizado aqui expressa a amplitude necessária do conceito de construção do profissional. Essa formação não abrange apenas o professor, mas também inclui os outros profissionais da educação, como os diretores, os orientadores educacionais, os supervisores pedagógicos e os administradores escolares. De acordo com Perrenoud, (2000) este termo foi utilizado na Declaração de Genebra, em 1996, documento elaborado por educadores. Essa expressão aparece nos Artigos 61 e 63 da atual LDB, como "capacitação em serviço" e "educação continuada", respectivamente.

16 Secretária de Políticas da Promoção da Igualdade Racial.

17 Programa de Ações Afirmativas para a População Negra nas Instituições de Educação Superior.
} 
os vários projetos dos diferentes departamentos desta instituição, portanto é um órgão de caráter interdepartamental, ligado a Pró-Reitoria de Graduação-PROGRAD, Pró-Reitoria de ExtensãoPROEX e Pró-Reitoria de Pesquisa-PPG.

Este órgão funciona a partir de estudos de um grupo de pesquisa certificado pelo CNPq intitulado por "Educação e Relações Étnicas com Ênfase em Culturas Afro-brasileiras". Este espaço possibilitou a criação de um programa que abarca projetos de pesquisas de docentes e de discentes da universidade, projetos de extensão desenvolvidos através de curso e outras atividades extensionistas, bem como, um curso de Pós-graduação Lato Sensu em Antropologia com Ênfase em Culturas Afro-brasileiras. O ODEERE tem como objetivo geral identificar possibilidades de eliminar preconceitos que geram discriminações com os saberes das culturas especialmente da Afro-brasileira e fornecer subsídios para que os/as docentes repensem sua formação frente ao desafio de trabalhar com os saberes da diversidade cultural. Esse objetivo se desdobrou em objetivos específicos, a saber: (a)Vivenciar situações teóricas-práticas que propiciem uma prática docente comprometida com os saberes das culturas afro-brasileiras; (b) Identificar saberes de legado africano que sofrem discriminações por conta de pré-concepções equivocadas nos saberes dos/as docentes; (c) Desenvolver oficinas de escrita que propiciem aos/as docentes, e aos outros cursistas ${ }^{18}$ que atuam em outras áreas, escreverem suas próprias histórias de vida. (d) Incentivar o desenvolvimento de pesquisas que ampliem os conhecimentos e subsidiem a execução de políticas educacionais para as comunidades remanescentes de quilombos e outros territórios negros, seja por parte dos docentes, assim como, de discentes nos diversos níveis de ensino. (e) Incentivar as pesquisas e as reflexões acerca dos processos educativos voltados para o conhecimento de matrizes culturais especialmente a africana. $(\mathrm{f})$ Identificar e coletar informações sobre as populações afro-brasileiras com o objetivo de subsidiar a formulação de políticas públicas voltadas para a diversidade nos sistemas de ensino.

Nesse aspecto, a proposta do programa ODEERE/UESB ganha uma dimensão muito maior, pois o seu alcance chega à formação do/a educador/a em serviço, uma vez que a maioria dos cursistas de seus programas de formação é composta por professores/as que atuam na educação básica. Nesse sentido, Nóvoa (1992) traz uma contribuição que vem elucidar essa questão ao afirmar que " estar em formação implica um investimento pessoal, um trabalho livre e criativo sobre os percursos e sobre os projetos próprios, com vistas à construção de uma identidade, que é também uma identidade profissional" (NÓVOA, 1992, p.25).

\footnotetext{
18 É válido lembrar que, além dos/as professores/as que atuam na educação básica, freqüentam também os cursos promovidos pelo ODEERE diretores de escolas, coordenadores pedagógicos, alunos de graduação e pessoas ligadas a movimentos sociais, sindicatos e a diferentes grupos religiosos.
} 
Muitos desses/as educadores/as vinculados aos trabalhos do ODEERE, buscam um referencial, um "norte" para iniciar um trabalho com a cultura afro-brasileira em seu lócus de atuação, seja ele formal ou informal. Melhor dizendo, um referencial que não fosse a antiga forma folclorizada presente em muitas situações de sala de aula e eventos culturais nos diferentes espaços educativos (ATAÍDE; MORAES, 1992).

Sabe-se que os/as docentes ainda encontram muitas dificuldades em trabalhar articulando Cultura e Educação, inclusive em função dos equívocos em relação ao conceito de cultura ao longo da história. Ademais, quando se trata especificamente da cultura afro-brasileira, existe ainda uma forma de resistência, por parte dos/as professores/as, em discutir essas questões e isso se deve, principalmente, ao fato de muitos desses/as educadores/as não terem ainda rompido com os seus ranços racistas, adquiridos ao longo da vivência em um ambiente cultural racista e segregador. Ou ainda, pelas deficiências de sua formação inicial em que a discussão acerca das questões raciais sempre ficou de fora do currículo. Desta forma, percebese como tais posturas interferem na prática docente destes sujeitos, impedindo que os mesmos rompam com estruturas do modelo eurocêntrico ainda presentes em suas práticas pedagógicas.

Quanto à formação do/a educador/a, sabe-se que ser educador é educar-se permanentemente, pois o processo educativo é contínuo. Paulo Freire (1996) afirmava com veemência que "quem ensina aprende ao ensinar e quem aprende ensina ao aprender"(FREIRE, 1996, p. 23), isto nos possibilita reconhecer que os conhecimentos produzidos pelos/as professores/as em seus diversos espaços de atuação, quer seja na escola, quer seja fora dela, vão implicar novas relações com outros conhecimentos que desdobrarão em novos olhares e, por conseguinte, em novas construções. Nessa perspectiva, a formação de professores/as em serviço é entendida como uma "formação contínua", e pode se dar no cotidiano e a partir do cotidiano profissional destes. Sobre essa questão Candau (1997) vem elucidar que a escola torna-se um importante lócus de formação continuada na medida em que a prática docente se converta em uma "prática reflexiva, uma prática capaz de identificar os problemas, de resolvêlos".(CANDAU, 1999, p. 57). A mesma autora refere-se à formação continuada promovida pelos diferentes sistemas de ensino e/ou centros educativos como "clássica" e é nessa perspectiva que citamos algumas experiências já concretizadas pelo ODEERE/UESB: 1) Curso de Especialização Lato Sensu em Antropologia com Ênfase em Culturas Afro-brasileiras, 2) Curso de Didática para o ensino de Culturas Afro-brasileiras; 3) Curso de extensão: "Educação e Culturas Afro-brasileiras".

O curso de Especialização em Antropologia com Ênfase em Culturas Afro-brasileiras, tem como objetivo geral identificar possibilidades de eliminar preconceitos que geram 
discriminações com os saberes das culturas especialmente da Afro-brasileira e fornecer subsídios para que os/as docentes repensem sua formação frente ao desafio de trabalhar com os saberes da diversidade cultural. A sua estrutura curricular está organizada da seguinte forma: o curso tem como carga horária trezentos e cinquenta horas de disciplinas e cento e quarenta horas para trabalho final, perfazendo um total de quatrocentos e noventa horas de curso, dividido em quatro etapas finalizando-as em doze meses.

O primeiro módulo busca estudar teorias da Antropologia, Fundamentos da Antropologia das Populações Afro-brasileiras e História e Cultura Africana e Afro-brasileira.O segundo módulo constará de cento e vinte horas divididas entre três disciplinas, cada uma delas com quarenta horas. A primeira disciplina se volta para um estudo dos métodos, técnicas e elaboração do projeto de pesquisa. A segunda estuda as teorias da Etnicidade e a terceira estuda as Relações Étnicas, Currículo e Formação Docente. 0 terceiro módulo, com seminários temáticos e duas disciplinas cada uma delas de trinta horas estuda na primeira disciplina as linguagens visuais e culturas e na segunda Diversidade Lingüística dos grupos Étnicos Africanos. O quarto módulo inclui a continuação da disciplina Métodos e Técnicas em trinta horas com apresentação preliminar do trabalho monográfico. Numa etapa seguinte acontece o Seminário de Pesquisa I em trinta horas.

O trabalho final é de caráter obrigatório em que o/a aluno/a escreve uma dissertação monográfica sobre dados teóricos/práticos antropológicos coletados e analisados, que deverá servir de acervo didático pedagógico do acervo documental bibliográfico e virtual do ODEERE.

$\mathrm{O}$ curso de extensão Educação e culturas Afro-brasileiras, também promovido pelo ODEERE/UESB, com financiamento do MEC/SEPPIR/UNIAFRO, propõe uma reflexão acerca das questões étnicas, inclusive as raciais no Brasil, tendo como referencial a história e a cultura da África e a sua contribuição na formação da identidade cultural do povo brasileiro. Nessa perspectiva, ampliar a discussão que privilegie a igualdade racial e cultural, apontando para a tomada de consciência é o maior desafio apresentado, tendo em vista a compreensão de que é fundamental a retomada de valores ético-estéticos dos vários povos que foram mantidos fora do currículo escolar, ao longo desse perverso processo colonialista homogeneizante.

O referido curso possui uma carga horária de 180 horas/aula, com aulas mensais, distribuídas em nove etapas. Na primeira etapa estuda-se a Antropologia das Populações Afrobrasileiras. Na segunda, as Linguagens Visuais das Culturas Afro-brasileiras. Já na terceira fazse um estudo sobre História Africana e Afro-brasileira. Na quarta etapa o trabalho é com a Diversidade Lingüística dos Grupos Étnicos no Brasil; na quinta etapa estuda-se Didática e Relações Étnicas. Na sexta desenvolvem-se estudos sobre a Pedagogia Simbólica. Numa 
sétima etapa, o grupo ocupa-se em reviver a tradição com o Caruru de São Cosme Damião, aproveitando para trabalhar costumes e culinária afro-brasileira. A oitava etapa, com 40 horas, conta com a participação dos/as cursistas no evento "Semana de Educação da Pertença Afrobrasileira" que já é promovido anualmente de 16 a 20/11. Como última etapa do curso, com carga horária de 28 horas, é realizada uma visita de campo a espaços de culturas afrobrasileiras em cidades do Recôncavo Bahiano com o objetivo de que os/as alunos/as do curso vivenciem na prática questões discutidas teoricamente durante as etapas do curso. Ao final desta visita os/as cursistas escrevem um relatório final em que articulam em seus escritos dados das visitas com sua história de vida.

O segundo curso de extensão denominado Didática para o ensino de Culturas Afro brasileiras tem como objetivo desenvolver atividades Didático-metodológicas para o ensino de História e Culturas Africanas e Afro-brasileiras. Busca-se com isto possibilitar que os/as docentes entendam o cotidiano e a historicidade como norteadores da teoria/prática que deve dar-se no ensino-aprendizagem. 0 público alvo são os/as professores/as que já concluíram 0 curso de "Educação e Culturas Afro-brasileiras ". Este é um curso com a proposta de oferecer 50 vagas, com a carga horária de 180 horas, com aulas mensais, distribuídas em oito etapas cada uma delas terá a duração de dezesseis horas. Para completar a carga horária os/as alunos/as deste curso devem prestar serviços no ODEERE, em especial no projeto ODEEREZINHO19

Todo esse trabalho é desenvolvido desde 2005, na cidade de Jequié, situada a $350 \mathrm{~km}$ da capital Salvador, e coordenado pela professora doutora Marise de Santana ${ }^{20}$, com a finalidade de atender aos/as educadores/as de toda região do Sudoeste da Bahia, já que a UESB é Universidade multicampi, sediada em três cidades do interior Bahiano: Jequié, Vitória da Conquista e Itapetinga.

\section{CONCLUSÕES INCONCLUSAS}

A escola, embora reconhecida por muitos teóricos como espaço de reprodução dos interesses e da cultura das classes hegemônicas (BOURDIEU; PASSERON, 2008), ela é também um espaço de confronto de forças, de mudanças. Nesse sentido, ela se mostra como espaço público e democrático que busca vivenciar relações de igualdade entre seus sujeitos na difícil tarefa de educar para a emancipação do homem. Nesse processo, alguns sujeitos se

19 O Projeto ODEEREZINHO visa educar crianças e adolescentes para, desde cedo, conviver com as diferenças, bem como, conhecer a história da cultura material e não material africana e afro-brasileira; educar-se enquanto descendente de africano para positivar sua identidade afro-brasileira. Este é um projeto direcionado para trabalhar com crianças que estejam matriculadas na rede oficial de ensino em parceria com a prefeitura municipal de Jequié.

$20 \quad$ Professora Adjunta da Universidade Estadual do Sudoeste da Bahia-UESB. 
revestem de importância considerável: os/as educadores/as. Pois essa tarefa não é atribuída apenas ao/a professor/a, mas também aos outros profissionais da educação, como os/as diretores/as, os/as orientadores/as educacionais, os/as supervisores/as pedagógicos e os/as administradores/as escolares, uma vez que a ação desses sujeitos não é isolada, ela se efetiva coletivamente e ganha ressonância além dos muros da escola. Por isso, pensar a formação do/a professor/a, quer seja inicial, quer seja continuada, é priorizar a elevação da qualidade do trabalho docente, com vistas à melhoria da ação pedagógica na escola e conseqüentemente da qualidade de vida da comunidade onde esta se encontra inserida.

Considerando as palavras do intelectual francês Edgar Morin na epígrafe, percebemos que as mesmas são reveladoras de que não somos apenas produtos da história, mas sujeitos dela. Pensar sob essa perspectiva no campo educativo, implica compreendermos a necessidade constante de repensarmos as nossas ações enquanto sujeitos históricos. Ademais, é preciso compreender que a formação é processo: um processo de formação do/a educador/a, de construção de sua "forma"21, que se dá pelo seu caminhar, pelo seu fazer-se. Ele/a se forma, se configura, no seu processo histórico de desenvolver-se.

Essa provocação nos permite reconhecer no/a educador/a um agente transformador que ocupa um papel relevante na construção de um ambiente educativo, social e democrático e, portanto, na construção de uma sociedade que valoriza a convivência com a diversidade.

Sabemos que a formação não pode ser considerada como o único fator determinante de uma boa atuação do/a profissional na educação. 0 atual momento histórico impõe algumas exigências a nós educadores/as, uma delas é que a escola ofereça respostas concretas à sociedade. $\mathrm{E}$ a atuação dos/as profissionais da educação, no que se refere à formação para a plena democracia, requer desses/as educadores/as, além do conhecimento adquirido em seu processo de formação, compromisso social e político com a docência (FREIRE, 1996).

A partir dessa compreensão, sabemos que a obrigatoriedade do ensino da história da África e da cultura africana, proposta pela legislação vigente, não representa a efetiva superação do racismo na escola e na sociedade como um todo. Mas acreditamos tratar-se de uma importante conquista que possibilita a construção de um ambiente educativo menos eurocêntrico

21 A palavra forma aqui não está sendo empregada no sentido aristotélico, segundo o qual todas as coisas são constituídas de matéria e forma, sendo a matéria aquilo do que o objeto é constituído e a forma a sua configuração própria, que a distingue de tudo o mais. Esse é o modelo essencialista, metafísico, abstrato de ver a formação. Mas compreendemos que a forma, a "essência" do educador, é constituída através de seus atos e de suas interações com o mundo e com os outros. 
e segregador, na medida em que seus/as educadores/as se comprometam efetivamente com as mudanças que se fazem necessárias e lutem para que, de fato, elas se materializem.

Sabe-se que há uma movimentação incipiente, entre algumas instituições, para criação de cursos com a finalidade de "capacitar" professores/as nessa área, mas sem avanços significativos. É fato também que muitas instituições da educação básica têm encampado propostas para se trabalhar os conteúdos exigidos pela lei 10.639/03, mas sabemos também que tais propostas são desenvolvidas no plano da superficialidade, apenas com a lembrança de alguns fatos em datas comemorativas, cumprindo o compromisso da escola com todas as "raças" e a vida voltando à normalidade. Aliás, o que a literatura específica aponta como principal dificuldade para que o trabalho de educação das relações étnico-raciais seja efetivamente executado no interior da escola, são as limitações dos/as professores/as em lidar com a temática, ainda presos a preconceitos e a desinformação.

A formação continuada dos/as profissionais da educação é uma necessidade para atender às exigências do cotidiano de seu exercício profissional, às solicitações dos estudantes e da sociedade em geral. Contudo, para a construção de novos conhecimentos acerca das questões étnico-raciais no cotidiano escolar e, por conseguinte, a transformação das práticas cotidianas dos/as professores/as, é preciso muito mais que capacitações isoladas ou comemorações estanques, mas é preciso mobilizar a construção de projetos em que a formação continuada dos/as professores/as seja vista como necessidade fundamental para a construção de um ambiente educativo verdadeiramente formador, onde seja dada ênfase a outros elementos que fazem parte do dia-a-dia da escola como seus ritos, símbolos, etc.

Assim sendo, entendemos que está mais do que tardio o enfrentamento das instituições formadoras dos/as profissionais da educação nessa luta pela construção de uma cultura de respeito e tolerância aos diferentes grupos étnicos que se fazem presentes também no interior do espaço escolar. Começando por um maior investimento na formação inicial e continuada de nossos/as educadores/as, pois, acreditamos que se as reformas educacionais não começarem pela valorização destes, de nada adianta muito a aprovação das leis.

Neste artigo, procuramos analisar a relação entre a educação para as relações étnicoraciais na educação básica como tentativa de implementação da Lei 10.639/03, inserida no bojo de importantes vitórias ocorridas no âmbito da educação do nosso país, e a sua relação com as propostas de formação continuada dos/as educadores pelo ODEERE/UESB. Experiência esta que buscou mostrar que apesar dos obstáculos impostos pela falta de uma cultura de valorização do legado africano pela escola, é possível proporcionar aos educadores/as uma 
formação na perspectiva da autonomia e respeito à diversidade, mesmo em uma sociedade com valores tão contraditórios. É possível construir caminhos que favoreçam uma educação para o respeito ao diferente sem querer que ele se torne igual.

\section{REFERÊNCIAS}

1. ATAÍDE, Yara Dulce Bandeira de; MORAIS, Edmilson de Sena. A (re)construção da identidade étnica afro-descendente a partir de uma proposta alternativa de educação pluricultural. Revista FAEEBA. Salvador, v. 1, n. 1, p. 81-98, jan-jun/1992.

2. BRASIL. Lei 10.639, de 09 de janeiro 2003. Altera a Lei 9.394 , de 20 de dezembro de 1996, que estabelece a diretrizes e bases da educação nacional, para incluir no currículo oficial da rede de ensino a obrigatoriedade da temática "História de Cultura Afrobrasileira". Diário Oficial da República federativa do Brasil, Poder Executivo, Brasília,DF, 10 de janeiro de 2003. Disponível em: http://www.diaadiaeducacao.pr.gov.br. Acesso em: out. de 2009.

3. BRASIL. Constituição: República Federativa do Brasil, Brasília: Horizonte Editora, 1988.

4. BRASIL. Ministério da Educação/Secretaria da Educação Continuada, Alfabetização e Diversidade. Orientações e Ações para a Educação das Relações Étnico-raciais. Brasília-DF: SECAD, 2006.

5. BOURDIEU, Pierre; PASSERON, Jean-Claude. A reprodução, elementos para uma teoria do sistema de ensino. Petrópolis, RJ: Vozes, 2008.

6. BURKE, Peter. (org). A escrita da história, novas perspectivas. São Paulo: UNESP, 1992.

7. CANDAU, Vera Maria (org). Magistério, construção cotidiana. Petrópolis, RJ: Vozes, 1999.

8. CAVALLEIRO, Eliane. Do silêncio do lar ao silêncio escolar. São Paulo: Summus, 2000.

9. FREIRE, Paulo. Saberes necessários à prática educativa. São Paulo: Paz e Terra, 1996.

10. GONÇALVES \& SILVA, Beatriz Petronilha. (Relatora). Parecer das Diretrizes Curriculares Nacionais para a Educação das Relações Étnico-Raciais e para 0 Ensino de História e Cultura Afro-Brasileira e Africana. Brasília: MEC/CNE, 2004.

11. HALL, Stuart. A identidade Cultural na pós-modernidade. Rio de Janeiro: DP\&A, 2006.

12. IANNI, Otávio. A dialética das relações raciais. Disponível em: <http://www. Sociologia.com.br/arti/colab/a16-oianni>. Acesso em nov. 2008.

13. NEVES, Gilberto. (org). Educar para a igualdade:combatendo o racismo na educação. Uberlândia: Sincopel, 2008.

14. NÓVOA, A. (coord). Os professores e sua formação. Lisboa: Publicações Dom Quixote, 1992.

15. PERRENOUD, Philippe. et. all. Formando professores profissionais. Quais estratégias? Quais competências? 2. Ed. Porto Alegre: Artmed, 2001.

16. RIOS, Ana Lugão; MATTOS, Hebe. Memórias do cativeiro, família, trabalho e cidadania no pós-abolição.Rio de Janeiro: Civilização Brasileira, 2005. 
17. ROMANELLI, Otaíza de Oliveira. História da educação no Brasil (1930/1973). Petrópolis, RJ: Vozes, 2003.

18. SACRISTÁN, J. Gimeno. 0 currículo: uma reflexão sobre a prática. Porto Alegre: ArtMed, 1998.

19. SANTANA, Marise de. 0 legado ancestral africano na diáspora e o trabalho do docente: desafricanizando para cristianizar. 2004. 224f. Tese (Doutorado em Ciências Sociais, Antropologia): PUC- SP, São Paulo, 2004.

20. SANTOS, Boaventura de Souza. Uma concepção multicultural dos direitos humanos. In: Lua Nova. Revista de Cultura e Política. n 39, p. 105-124. São Paulo: CEDEC, 1997.

21. _ (Org.). Reconhecer para libertar: os caminhos do cosmopolitismo multicultural. Rio de Janeiro: Civilização Brasileira, 2003.

22. SANTOS, Milton. 0 espaço do cidadão. $2^{a}$ ed. São Paulo: Nabel,1992.

23. SANTOS, Sales Augusto dos. A Lei no 10.639/03 como fruto da luta anti-racista do Movimento Negro. In Educação anti-racista : caminhos abertos pela Lei Federal $n^{0}$ 10.639/03 /Secretaria de Educação Continuada, Alfabetização e Diversidade. - Brasília: Ministério da Educação, Secretaria de Educação Continuada, Alfabetização e Diversidade, 2005. p. 21

24. SILVA, Tomaz Tadeu da. Cultura, Identidades sociais: territórios contestados. Petrópolis RJ: Vozes, 1995. 